\title{
Differential effects of Radix Paeoniae Rubra (Chishao) on cytokine and chemokine expression inducible by mycobacteria
}

Liangjie Wang ${ }^{1}$, Cindy Lai Hung Yang ${ }^{1}$, Terry Cho Tsun $\mathrm{Or}^{2}$, Gang Chen ${ }^{4}$, Jian Zhou ${ }^{4}$, James Chun Bong Li ${ }^{1,2}$ and Allan Sik Yin Lau ${ }^{1,2,3^{*}}$

\begin{abstract}
Background: Upon initial infection with mycobacteria, macrophages secrete multiple cytokines and chemokines, including interleukin-6 (IL-6), IL-8 and tumor necrosis factor- $\alpha$ (TNF- $\alpha$ ), to mediate host immune responses against the pathogen. Mycobacteria also induce the production of IL-10 via PKR activation in primary human monocytes and macrophages. As an anti-inflammatory cytokine, over-expression of IL-10 may contribute to mycobacterial evasion of the host immunity. Radix Paeoniae Rubra (RPR, Chishao), a Chinese medicinal herb with potentials of anti-

inflammatory, hepatoprotective and neuroprotective effects, is used to treat tuberculosis. This study investigates the immunoregulatory effects of RPR on primary human blood macrophages (PBMac) during mycobacterial infection.

Methods: The interaction of Bacillus Calmette-Guerin (BCG) with PBMac was used as an experimental model. A series of procedures involving solvent extraction and fractionation were used to isolate bioactive constituents in RPR. RPR-EA-S1, a fraction with potent immunoregulatory effects was obtained with a bioactivity guided fractionation scheme. PBMac were treated with crude RPR extracts or RPR-EA-S1 before BCG stimulation. The expression levels of IL-6, IL-8, IL-10 and TNF- $\alpha$ were measured by qPCR and ELISA. Western blotting was used to determine the effects of RPR-EA-S1 on signaling kinases and transcriptional factors in the BCG-activated PBMac.

Results: In BCG-stimulated macrophages, crude RPR extracts and fraction RPR-EA-S1 specifically inhibited IL-10 production while enhanced IL-8 expression at both mRNA and protein levels without affecting the expressions of IL- 6 and TNF- $\alpha$. Inhibition of BCG-induced IL-10 expression by RPR-EA-S1 occurred in a dose- and time-dependent manner. RPR-EA-S1 did not affect the phosphorylation of cellular protein kinases including MAPK, Akt and GSK3 $\beta$. Instead, it suppressed the degradation of $\mid \kappa B \alpha$ in the cytoplasm and inhibited the translocation of transcription factor NF- $\kappa$ B1 p50 to the nucleus.
\end{abstract}

Conclusion: RPR crude extracts and its fraction RPR-EA-S1 inhibited anti-inflammatory cytokine IL-10 and enhanced pro-inflammatory chemokine IL-8 expression in BCG-activated PBMac. The inhibitory effects of RPR-EA-S1 on IL-10 expression in BCG-activated PBMac may be due to the reduced nuclear translocation of NF- $\kappa$ B1 p50.

\section{Background}

Tuberculosis (TB) remains a major cause of morbidity and mortality worldwide as a result of Mycobacterium tuberculosis (Mtb) infection. In 2008, an estimated 9.4 million new cases of TB and 1.3 million deaths were recorded globally [1]. Although anti-TB drugs and

\footnotetext{
* Correspondence: asylau@hkucc.hku.hk

'Molecular Chinese Medicine Laboratory, Li Ka Shing Faculty of Medicine,

The University of Hong Kong, Pokfulam, Hong Kong SAR, PR China

Full list of author information is available at the end of the article
}

vaccines have been used for decades, the emergence of multidrug-resistant TB (MDR-TB) and the co-infection of Mtb and related mycobacteria with human immunodeficiency virus (HIV) pose new challenges to the treatment of TB [1,2].

Upon Mtb infection, multiple immune cells including macrophages/monocytes [3], dendritic cells (DCs) [4], neutrophils [5], natural killer cells [6] and T cells [6] are activated to mediate host defense against the pathogen. Among these cell types, macrophages are the main

\section{Biomed Central}


immunocytes in initiating innate immunity against Mtb. Macrophages are professional antigen presenting cells that are important in bridging innate and adaptive immunity [7]. Macrophages exert their direct antimicrobial effects through phagocytosis [8], generation of reactive oxygen intermediates (ROIs) and reactive nitrogen intermediates (RNIs) [9], autophagy [10], activation of vitamin D pathway [11], apoptosis [12] and secretion of cytokines and chemokines [13].

Specific cytokines and chemokines produced by macrophages during Mtb infection play important roles in regulating the host innate and adaptive immune responses [13]. For example, tumor necrosis factor- $\alpha$ (TNF- $\alpha$ ) enhances the activity of macrophage to kill replicating Mtb in synergy with interferon- $\gamma$ (IFN- $\gamma$ ) [14] and contributes to the formation of granuloma and prevention of mycobacterial dissemination through decreased cell migration [15]. Another key cytokine is interleukin-6 (IL-6), which is a pro-inflammatory cytokine that regulates $\mathrm{B}$ and $\mathrm{T}$ cell activities and contributes to the initial innate responses to Mtb [16].

IL-8, another important chemokine against Mtb, is primarily secreted by monocytes and macrophages but also produced by fibroblasts, keratinocytes, and lymphocytes [17]. The induction of IL- 8 can be stimulated by multiple factors including pathogens, toxins and cytokines [18]. Previous studies have demonstrated the connection between IL- 8 production and Mtb infection. In clinical studies, remarkably elevated levels of IL-8 were found in tuberculous pleural exudate, bronchoalveolar lavage fluid, cerebrospinal fluid and tuberculous granulomas [19]. In contrast, decreased IL-8 secretion was observed in HIVinfected patients with miliary TB, suggesting that the absence of IL-8 induction is detrimental to restricting Mtb dissemination [20]. Such important role of IL-8 was illustrated in a previous study that upon Mtb infection IL- 8 attracted neutrophils and T lymphocytes to the infection sites at an early stage, resulting in the formation of granuloma [21].

Unlike the pro-inflammatory cytokines IL-6 and IL-8, interleukin-10 (IL-10) is a key anti-inflammatory cytokine produced by macrophages, Th1 cells [22], Th2 cells [22], regulatory $\mathrm{CD}^{+} \mathrm{T}$ cells [23], $\mathrm{CD}^{+} \mathrm{T}$ cells [23], DCs and B cells [24]. IL-10 mainly plays a negative role in the regulation of immunity to prevent uncontrolled responses to pathogens $[25,26]$. It inhibits the production of pro-inflammatory cytokines, such as IFN- $\gamma$, IL-12, IL-18, IL-1 and TNF- $\alpha$, by macrophages and DCs [27]. Together with reduced induction of inducible nitric oxide synthases (iNOS) and ROIs, IL-10 expression results in reduced killing of intracellular pathogens by macrophages [28]. IL-10 is also an inhibitor of antigen presentation by macrophages and DCs through down- regulation of MHCII expression [29-31]. In the event of TB progression, over-expression of IL-10 results in a higher mycobacterial burden and reactivation of pulmonary TB [32]. Macrophages from IL-10 deficient mice, when challenged with $\mathrm{BCG}$, produce higher levels of TNF- $\alpha$ with concomitant accelerated clearance of mycobacteria [33]. These observations were further validated by clinical studies, showing higher levels of IL-10 production in patients with active pulmonary $\mathrm{TB}$ $[34,35]$. Moreover, overproduction of IL-10 by $\mathrm{T}$ cells was shown to be related to suppressed immunity and increased susceptibility to mycobacteria infection [36].

Radix Paeoniae Rubra (RPR, Chishao), the dried root of Paeonia lactiflora Pallas or Paeonia veitchii Lunch [37], has been widely used by Chinese medicine practitioners to treat cardiovascular, inflammation and female reproductive diseases [38]. Based on the principle of Chinese medicine, historical literatures described RPR with the functions of tonifying blood, cooling blood, cleansing heat, and invigorating blood circulation. It is often used as an "Assistant" herb to counteract or ameliorate the undesirable side effects of the "King" herbs [37]. In contemporary literatures, RPR is used for the treatment of the following diseases: seasonal febrile diseases with eruptions, bleeding, menstrual disorders, trauma, skin infection and conjunctivitis as well as pain over the chest, hypochondrium and abdomen [39]. RPR is also used in some herbal formulae to treat TB patients [40]. RPR has protective effects on lung injury through the induction of heme oxygenase-1 (HO-1) and suppression of nitric oxide $(\mathrm{NO})$ in rats $[41,42]$. In a mouse model, the extracts obtained from RPR and Astragalus membranaceus protected the liver from BCG/endotoxin-induced injury. These protective effects were associated with downregulation of pro-inflammatory cytokines [43]. While some studies on the biological effects and chemical constituents of RPR have been reported [38], the immunoregulatory effects of RPR and their detailed mechanisms of action at cellular signaling levels are yet to be investigated, especially the interaction of BCG with human blood macrophages.

In the present study, an active fraction, namely RPREA-S1, was isolated from the crude extracts of RPR using a bioactivity-guided fractionation scheme. The chemical profile of RPR-EA-S1 was analyzed by high performance liquid chromatography (HPLC) and gas chromatography mass spectrometry (GC-MS). The regulatory effects of crude RPR extract and its fraction RPR-EA-S1 on BCG-induced cytokine and chemokine expression in human PBMac were examined. The underlying mechanisms of the inhibitory effects of RPR-EA-S1 on BCG-induced IL-10 expression were delineated. 


\section{Methods}

Plant material

Radix Paeoniae Rubra was obtained from PuraPharm International Ltd. (Hong Kong, China). The raw material of the herb was authenticated by PuraPharm Corporation (Guangxi, China) according to the method in the Pharmacopoeia of the People's Republic of China 2005 [44] which states that the RPR sample should not contain less than $1.8 \%$ of paeoniflorin, calculated with reference to the dried substance. The Radix Paeoniae Rubra used in our study contained more than $4 \%$ of paeoniflorin.

\section{Preparation of the crude extract from Radix Paeoniae Rubra}

The procedures for raw herb extraction and fractionation were shown in Figure 1. Briefly, the herbs (300 g) were ground into powder and extracted with eight folds (volume) of Milli Q water (Sartorius, Germany) under reflux for one hour. The extraction was repeated for three times. The resulting extracts were combined and concentrated at $70^{\circ} \mathrm{C}$ under reduced pressure until the density reached $1.28 \mathrm{~g} / \mathrm{mL}$. Then the paste collected was precipitated with five folds (volume) of ethanol (EtOH). After filtration, the supernatant was evaporated to dryness in an evaporator (Rotavapor R-200, BUCHI, Switzerland), yielding crude RPR extract (81 g). The extract was then dissolved in methanol $(\mathrm{MeOH})$ and partitioned with an equal volume of hexane $\left(n-\mathrm{C}_{6} \mathrm{H}_{14}\right)$ for three times. The $\mathrm{MeOH}$ extract was dried and re-dissolved in water and then partitioned sequentially with an equal volume of ethyl acetate (EtOAc) and $n$-butanol $(n-\mathrm{BuOH})$ for four times. Four fractions were obtained, namely RPR-H, RPR-EA (10 g), RPR-Bu and RPR-W. According to a bioassay guided scheme, the fraction RPR-EA with the most potent activity on IL-10 suppression was selected and further separated by silica gel column chromatography (Merck, Germany). After loading

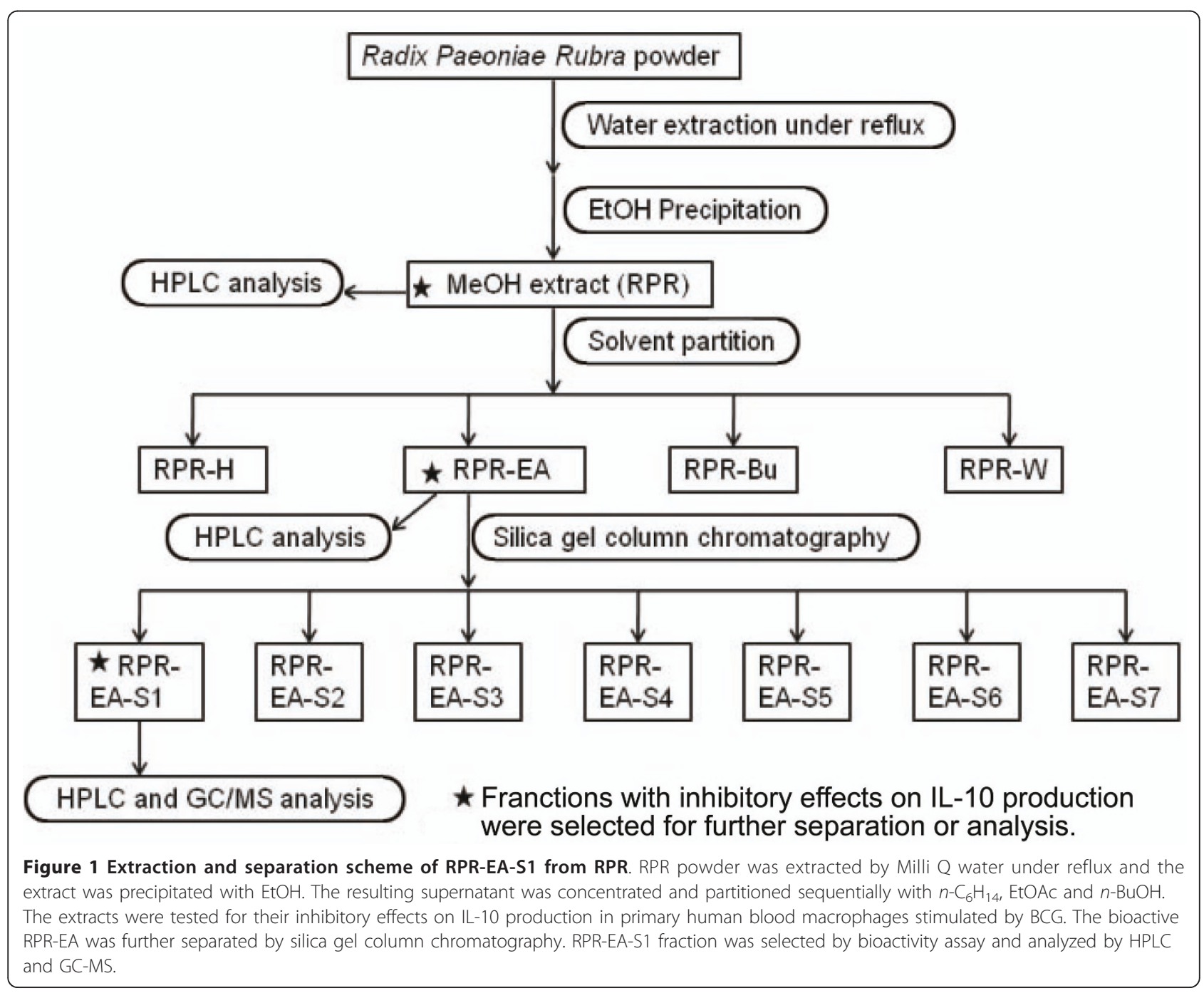


the sample, the column was washed sequentially with a series of solvents: $50 \% n-\mathrm{C}_{6} \mathrm{H}_{14}$ in EtOAc, $100 \%$ EtOAc, EtOAc combined with $10 \%, 30 \%, 50 \%$ or $70 \%$ of $\mathrm{MeOH}$ and finally $100 \% \mathrm{MeOH}$. These serial washings yielded seven fractions: RPR-EA-S1 (0.78 g), RPR-EA-S2, RPREA-S3, RPR-EA-S4, RPR-EA-S5, RPR-EA-S6 and RPREA-S7.

\section{Chemicals and antibodies}

All the chemical solvents such as $\mathrm{EtOH}, \mathrm{MeOH}$, $n$-BuOH, EtOAc and $n-\mathrm{C}_{6} \mathrm{H}_{14}$ were purchased from Merck (Germany). Antibodies against NF- $\kappa \mathrm{B} 1 \mathrm{p} 50$, actin, $\mathrm{I} \kappa \mathrm{B} \alpha$ and Lamin $\mathrm{B}$ were purchased from Santa Cruz Biotechnology (USA). Antibodies against phospho-ERK1/2, phospho-p38, phospho-Akt and phosphoGSK3 $\beta$ as well as antibodies against total ERK1/2, p38, Akt and GSK3 $\beta$ were purchased from Cell Signaling Technology (USA). Anti-rabbit IgG HRP-conjugated secondary antibodies were purchased from BD Biosciences (USA). Anti-goat IgG HRP-conjugated secondary antibodies were purchased from ZYMED Laboratory (USA).

\section{Bacillus Calmette-Guerin}

Bacillus Calmette-Guerin (BCG) is a live freeze-dried vaccine made from an attenuated strain of Mycobacterium bovis, Danish strain 1331. The vaccine, which contains no virulent Mtb, was purchased from Statens Serum Institut (Denmark).

\section{Isolation of primary human peripheral blood macrophages}

Using Ficoll-Paque (GE Healthcare, USA) density gradient centrifugation as previously described [3,29], we isolated primary human peripheral blood macrophages (PBMac) from buffy coats of healthy blood donors obtained from the Hong Kong Red Cross Blood Transfusion Service. Briefly, the fresh blood samples were centrifuged at 3000 rpm (1811g, Eppendorf AG, Germany) for 20 minutes and separated into plasma and blood cell layers. The plasma layer was carefully removed and heat-inactivated for 30 minutes at $56^{\circ} \mathrm{C}$ in water bath, followed by chilling on ice for ten minutes. It was centrifuged at $4000 \mathrm{rpm}(3220 \mathrm{~g}$, Eppendorf AG, Germany) for ten minutes to remove the precipitates. The clear supernatant was then filtered through $0.45 \mu \mathrm{m}$ membranes and later used as the autologous plasma added to culture macrophages. The blood cell layer was diluted with an equal volume of phosphate buffered saline (PBS) at a ratio of 1:1 and then slowly overlaid over the Ficoll and centrifuged for 20 minutes at 2300 rpm (1065g, Eppendorf AG, Germany). The white blood cell layer was removed and washed with RPMI 1640 (Invitrogen, USA) for three times and the supernatant was clear after washes. The cell pellet was re-suspended with
RPMI medium containing 5\% autologous plasma and 1\% penicillin/streptomycin and plated onto a tissue culture Petri dish. The dish was incubated at $37^{\circ} \mathrm{C}$ in a humidified atmosphere with $5 \% \mathrm{CO}_{2}$ for one hour to allow monocytes to adhere. The unattached cells were washed away by warm RPMI medium and the adherent monocytes were incubated at $37^{\circ} \mathrm{C}$ overnight. Subsequently, cold RPMI medium with $5 \mathrm{mM}$ ethylenediaminetetraacetic acid (EDTA) was used to wash and detach the monocytes, which were finally seeded onto the tissue culture plates in RPMI medium supplemented with 5\% autologous plasma and $1 \%$ penicillin/streptomycin. After 14 days of culturing, with replenishment of medium every three to four days, the monocytes derived macrophages were ready for treatment.

\section{Total RNA extraction and reverse transcription}

Total RNA was extracted with TRIzol Reagent (Invitrogen, USA). SuperScript II transcriptase (Invitrogen, USA) was used to synthesize cDNA from the total RNA according to the manufacturer's instructions. The cDNA samples were kept at $-20^{\circ} \mathrm{C}$ until use.

\section{Quantitative real-time PCR}

The expression levels of IL-6, IL-8, IL-10 and TNF- $\alpha$ mRNA were determined with quantitative real-time PCR (q-PCR) on an ABI 7500 system using TaqMan (Applied Biosystems, USA). The relative quantification method was used to calculate the mRNA expression levels [45]. Briefly, we applied a $20 \mu \mathrm{L}$ reaction system containing the sample cDNA, TaqMan $2 \times$ Master Mix, TaqMan probes for target genes (gene-specific Assayson-Demand reagent kits, Applied Biosystems, USA) and TaqMan probe for $18 \mathrm{~s}$ rRNA as the internal control. Each sample was run in duplicates. The threshold cycle number $(\mathrm{Ct})$ of the target gene was normalized to the Ct of $18 \mathrm{~S}$ rRNA for each sample $(-\Delta \mathrm{Ct})$. The $-\Delta \mathrm{Ct}$ value of the mock-treated sample was subtracted from the $-\Delta \mathrm{CT}$ value of other samples, yielding $-\Delta \Delta \mathrm{Ct}$. And the value of $2^{-\Delta \Delta C t}$ refers to the fold change of target gene's mRNA expression level compared to that of the corresponding mock-treated sample.

\section{Enzyme-linked immunosorbent assay (ELISA)}

To study the RPR's differential effects on cytokines inducible by BCG, we applied ELISA to measure the amounts of IL-6, IL-8, IL-10 and TNF- $\alpha$ in the cell culture supernatants. Briefly, macrophages (PBMac) derived from human primary monocytes were seeded onto a 24 -well plate at a concentration of $10^{6} / \mathrm{mL}$. After pretreatment of PBMac with the RPR extract or its designated partially purified fractions for 16 hours, BCG $(\mathrm{MOI}=1)$ was added to the cell cultures. After 24 hours of incubation, the supernatants were collected 
and the concentrations of cytokines were measured with ELISA according to the manufacturer's instructions (R\&D Systems, USA).

\section{Western blot analysis}

Cytoplasmic proteins and nuclear proteins were extracted separately with buffer A and buffer $\mathrm{C}$ as previously described [46] with modifications. Cells were washed twice with cold PBS and lysed on ice with buffer A (10 mM HEPES pH 7.9, $10 \mathrm{mM} \mathrm{KCl,} 0.1 \mathrm{mM}$ EDTA, $0.1 \mathrm{mM}$ EGTA, $1 \mathrm{mM}$ DTT, $0.5 \mathrm{mM}$ PMSF, $2 \mu \mathrm{g} / \mathrm{mL}$ aprotinin, $1 \mathrm{mM}$ sodium orthovanadate, $2 \mu \mathrm{g} / \mathrm{mL}$ pepstatin, $2 \mu \mathrm{g} / \mathrm{mL}$ leupeptin and $50 \mathrm{mM}$ sodium fluoride) for 15 minutes. Then $10 \% \mathrm{NP}-40$ was added to the cells at a final concentration of $0.625 \%$, followed by several seconds of vortexing. The cells were then removed with a clean scraper. The lysate was then centrifuged at $15000 \mathrm{~g}$ for 30 seconds. The supernatant containing cytoplasmic proteins was stored at $-70^{\circ} \mathrm{C}$ until use. The pellet was washed gently with buffer $\mathrm{A}$ and centrifuged again (15000g, Eppendorf AG, Germany) to obtain a pellet by discarding the supernatant. The nuclear proteins were extracted by re-suspending the pellet in buffer $\mathrm{C}$ (20 mM HEPES pH 7.9, 0.4 M NaCl, 1 mM EDTA, $1 \mathrm{mM}$ EGTA, $1 \mathrm{mM}$ DTT, $1 \mathrm{mM}$ PMSF, $1 \mu \mathrm{g} / \mathrm{mL}$ aprotinin, $1 \mathrm{mM}$ sodium orthovanadate, $2 \mu \mathrm{g} / \mathrm{mL}$ pepstatin, $2 \mu \mathrm{g} / \mathrm{mL}$ leupeptin and $50 \mathrm{mM}$ sodium fluoride). The sample was lysed on ice for 15 minutes with vortexing every five minutes. The nuclear extract was centrifuged (15000g, Eppendorf AG, Germany) at $4^{\circ} \mathrm{C}$ for five minutes and the supernatant was stored at $-70^{\circ} \mathrm{C}$ until use.

Protein concentrations were quantified with the BioRad protein assay kit (USA). Then an equal amount of proteins $(30 \mu \mathrm{g}$ of cytoplasmic or $4 \mu \mathrm{g}$ of nuclear proteins) was separated by $10 \%$ SDS-PAGE and transferred to a nitrocellulose membrane. After three hours of incubation with $1 \%$ BSA in tris-buffered saline Tween-20 (TBST), the membrane was incubated with a specific antibody (1:1000 dilution) to the protein of interest for overnight at $4^{\circ} \mathrm{C}$. Then the membrane was washed with TBST and incubated with the corresponding secondary antibody (1:4000 dilution) for one hour at room temperature. After five times of washes, the bands in the membrane were detected with a GE Healthcare Enhanced Chemiluminescence System (USA) according to the manufacturer's instructions. ImageJ (National Institutes of Health, USA) was used to quantify the levels of proteins captured in the laser densitometry results.

\section{MTT assay}

MTT (3-(4,5-dimethylthiazol-2-yl)-2,5-diphenyltetrazolium bromide) assays were used to test the cytotoxicity of the RPR extract and its partially purified fractions on the cells. PBMac were seeded at a concentration of
$10^{6} / \mathrm{mL}$ in a 24 -well plate. After 48 hours of treatment with the RPR extract or its designated fractions, the cells were incubated with RPMI 1640 medium containing $0.5 \mathrm{mg} / \mathrm{mL} \mathrm{MTT} \mathrm{(Invitrogen,} \mathrm{USA)} \mathrm{for} \mathrm{one} \mathrm{hour.}$ Then the cell culture medium was removed and isopropanol (IPP) was added to the wells and incubated at room temperature for ten minutes. Absorbance values of the culture medium at $570 \mathrm{~nm}$ were measured with a microplate reader (Bio-Rad, USA).

\section{High performance liquid chromatography (HPLC) analysis of the extracts}

The RPR extract and its fractions were dissolved in HPLC grade $\mathrm{MeOH}$ (Merck, Germany) before analysis. HPLC was performed with an Agilent 1200 liquid chromatography system (Agilent, USA) equipped with a reverse-phase HPLC column (Lichrospher 100, RP $\mathrm{C}_{18}$ EC $5 \mu \mathrm{m}, 250 \times 4.6 \mathrm{~mm}$ ID) described in our previous reports $[47,48]$. A gradient elution from $10 \%$ acetonitrile $\left(\mathrm{CH}_{3} \mathrm{CN}\right)$ to $90 \% \mathrm{CH}_{3} \mathrm{CN}$ at a flow rate of $1 \mathrm{~mL} / \mathrm{min}$ was used to separate the peaks which were detected at $210 \mathrm{~nm}$ with an Agilent 1200 series (Agilent, USA), a fast scanning photodiode array detector.

\section{Gas chromatography mass spectrometry}

Before GC-MS analysis, the RPR extracts first underwent silylation. Briefly, $100 \mu \mathrm{L}$ RPR-EA-S1 in $\mathrm{CH}_{3} \mathrm{CN}$ was mixed with $50 \mu \mathrm{L}$ of pyridine and $50 \mu \mathrm{L}$ of the derivatizing agent BSTFA [N, O-bis(trimethylsilyl)trifloroacetamide] in a $1 \mathrm{~mL}$ reaction vial (Alltech, USA). After incubation for two hours at $70^{\circ} \mathrm{C}$, bis-trimethyl silyl trifluoroacetamide (BSTFA) replaced the labile hydrogen atom with a $-\mathrm{Si}\left(\mathrm{CH}_{3}\right)_{3}$ group on a wide range of polar compounds. Then the resulting mixture was analyzed by GC-MS (GC: 7890A, MS: 5975C, Agilent, USA) equipped with a HP-5MS column (Agilent, USA) $(30 \mathrm{~m} \times 250 \mu \mathrm{m}$ $\times 0.25 \mu \mathrm{m})$. The sample $(1 \mu \mathrm{l})$ was injected to the column. Helium was used as the carrier gas at a flow rate of $1 \mathrm{~mL} / \mathrm{min}$. The oven temperature was started at $70^{\circ} \mathrm{C}$ for one minute, and then increased to $180^{\circ} \mathrm{C}$ at a rate of $10^{\circ} \mathrm{C} / \mathrm{min}$; after two minutes' holding, increased to $280^{\circ} \mathrm{C}$ at a rate of $10^{\circ} \mathrm{C} / \mathrm{min}$ and held for three minutes. The interface temperature was $250^{\circ} \mathrm{C}$, ion source temperature was $230^{\circ} \mathrm{C}$, and electron impact ionization (EI) was at $200 \mathrm{eV}$. Mass spectra were analyzed in the range of 50-700 atom mass units (amu) for a run time of 22 minutes. The G1701EA Chemstation (Agilent, USA) was used to perform the MS data analysis. The peaks of the eluants with more than $90 \%$ similarity to the compounds listed in the NIST GC-MS library were selected.

\section{Statistical analysis}

All data were presented as the mean \pm standard deviation (SD). Data were analyzed with the SPSS statistical 
package (version 11.5.0, SPSS Inc, USA). The statistical differences in the respective protein levels and mRNA levels among treatments were tested by one-way ANOVA followed by an Honestly Significant Difference (HSD) post-hoc Tukey test. $P$ value of less than 0.05 is considered statistically significant.

\section{Results}

\section{Extraction and bioassay guided fractionation of RPR}

Using solvent partitioning extraction, we obtained RPRH, RPR-EA, RPR-Bu and RPR-W. MTT assays showed that all four fractions were not toxic to PBMac at 50 $\mu \mathrm{g} / \mathrm{mL}$ (Additional file 1). Therefore, each fraction at 50 $\mu \mathrm{g} / \mathrm{mL}$ was tested for their inhibitory effects on BCG (MOI $=1$, MOI: multiplicity of infection) induced IL-10 production in PBMac. We reported previously that 24 hours of BCG stimulation was an optimal time point for studying BCG-induced IL-10 expression [30]. The present study used the same time point. The ELISA assays found that PBMac pretreated with RPR-EA showed $68 \%$ reduction in IL-10 production induced by BCG while RPR-H, RPR-Bu and RPR-W did not show any inhibitory effect (Figure 2A). Using silica gel column chromatography, we further separated RPR-EA, the most potent fraction, into seven sub-fractions, namely RPR-EA-S1 to RPR-EA-S7 (Figure 1). Additional MTT assays demonstrated that none of them was toxic to PBMac at $50 \mu \mathrm{g} / \mathrm{mL}$ (Additional file 2). The ELISA results found that pretreatment of PBMac with fractions RPR-EA-S1, RPR-EA-S2 and RPR-EA-S6 $(20 \mu \mathrm{g} / \mathrm{mL})$ showed $66 \%, 40 \%$ and $62 \%$ reduction of BCG-induced IL-10 production respectively whereas the remaining fractions did not have inhibitory effects (Figure 2B). RPR-EA-S1, the most biologically active fraction, was selected for further analysis and investigation. The chemical profiles of the crude RPR extract as well as RPREA and RPR-EA-S1 were analyzed with reverse phase HPLC (Additional file 3).

\section{Differential effects of RPR extracts on BCG-induced cytokine and chemokine expression}

Since cytokines and chemokines secreted by macrophages play a critical role in the host immune responses against mycobacteria, we examined the RPR's regulatory effects on BCG-induced IL-6, IL-8, IL-10 and TNF- $\alpha$ expression in PBMac. Pretreatment of the immune cells with RPR extract had no effect on BCG-induced IL-6 or TNF- $\alpha$ expression; however, it significantly reduced the production of IL-10 and increased that of IL- 8 at both mRNA and protein levels (Figure 3). The differential effects of RPR on BCG-induced cytokine and chemokine expression were further confirmed with three batches of RPR extracts (Additional file 4).

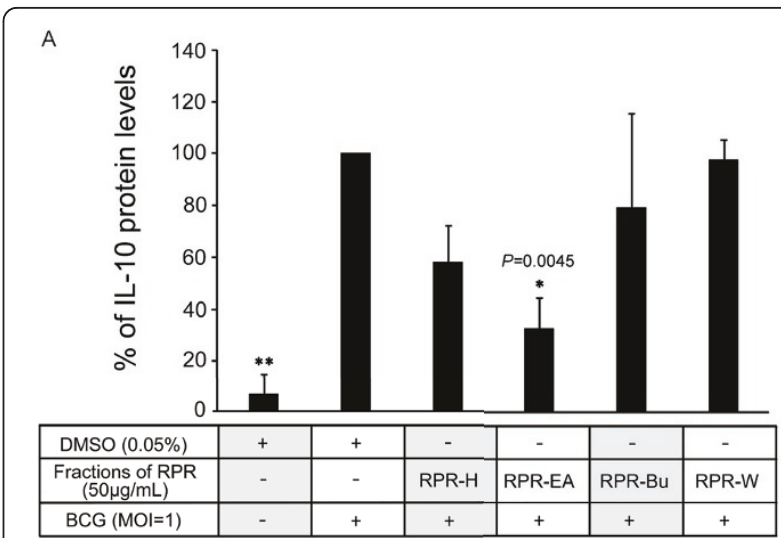

B

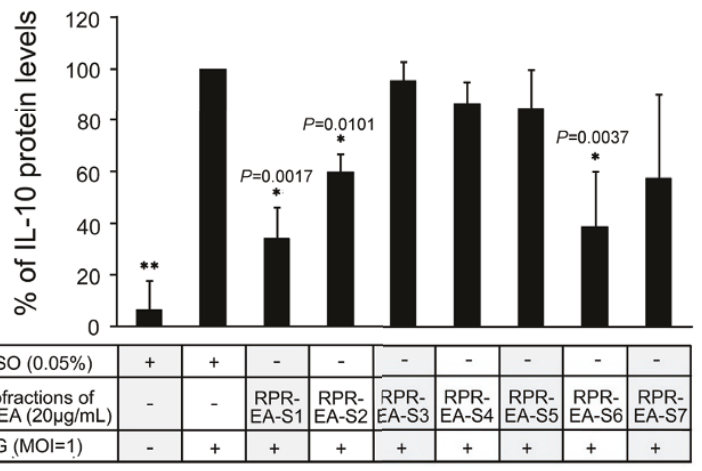

Figure 2 Bioassay guided fractionation of RPR. PBMac $\left(5 \times 10^{5}\right)$ were pretreated with $0.05 \%$ DMSO or the indicated RPR fractions (A) or RPR-EA subfractions (B) overnight and then stimulated with BCG $(\mathrm{MOI}=1)$. Culture supernatants were collected after 24 hours. The levels of IL-10 in the supernatants were measured by ELISA. The IL-10 concentration in the supernatant of DMSO + BCG sample was set as $100 \%$, and the rest were compared to it to obtain a percentage value. Results are shown as mean \pm SD from independent experiments on PBMac obtained from three different healthy donors. ${ }^{*} P<0.05,{ }^{*} P<0.001$ compared to the DMSO + BCG sample (one-way ANOVA, Tukey's test).

Differential effects of RPR-EA-S1 on BCG-induced cytokine and chemokine expression

To investigate whether the partially purified fraction RPR-EA-S1 contained the immuno-regulatory activity derived from the crude RPR extract, we performed ELISA on IL-6, IL-8, IL-10 and TNF- $\alpha$. RPR-EA-S1's regulatory patterns on the four cytokines or chemokines were similar to those of RPR crude extracts (Figure 3 and 4). RPR-EA-S1 inhibited IL-10 and enhanced IL-8 expression, while had no effect on IL-6 and TNF- $\alpha$ expression in the BCG-induced PBMac. When compared to the crude RPR extract (Figure 3B), RPR-EA-S1 was more effective in terms of the levels of IL-10 inhibition and IL-8 induction in BCG-stimulated PBMac (Figure 4). 
A
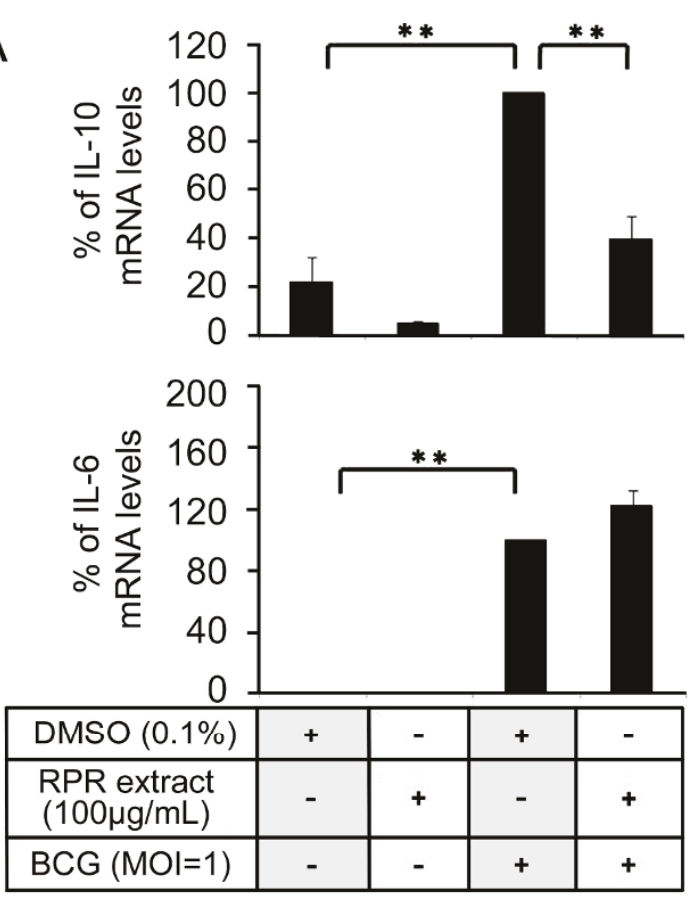

B
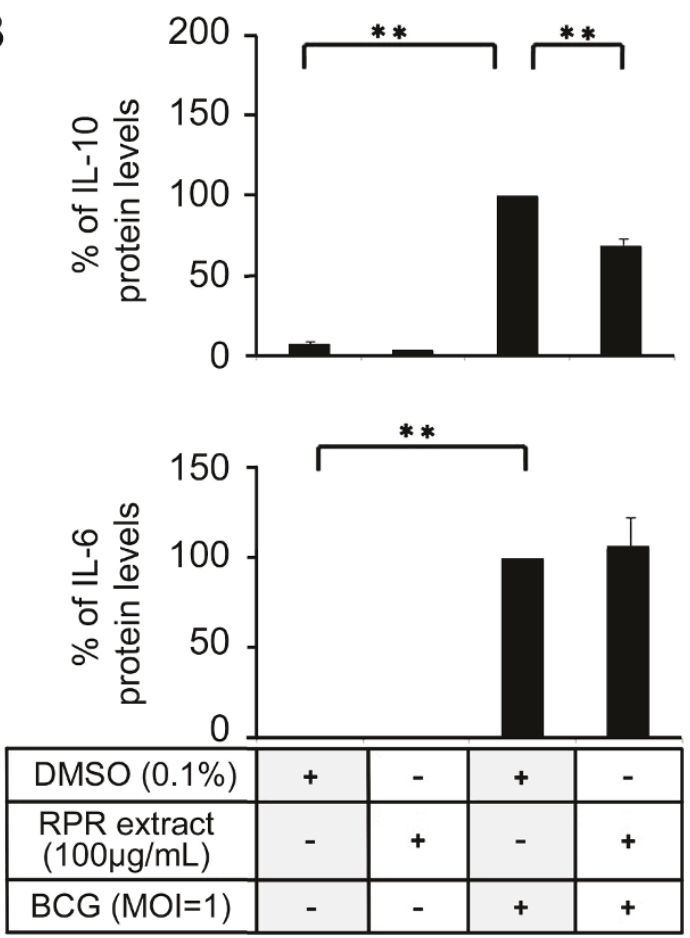
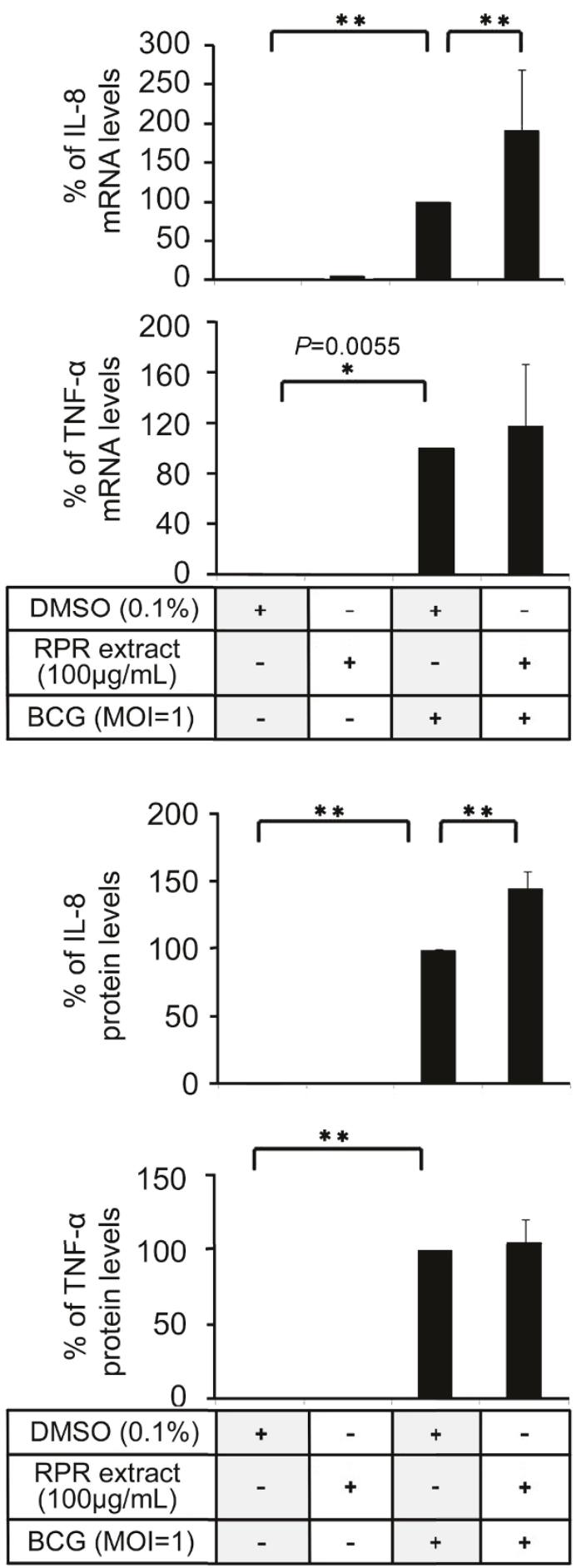

Figure 3 Effects of RPR crude extract on the expression levels of cytokines in BCG-stimulated PBMac. PBMac $\left(5 \times 10^{5}\right)$ were pretreated with $0.1 \%$ DMSO or $100 \mathrm{\mu g} / \mathrm{mL}$ RPR extract overnight and then stimulated with $\mathrm{BCG}(\mathrm{MOI}=1)$. (A) Total mRNA was extracted after 3 hours for CDNA synthesis. The levels of mRNA were determined by q-PCR. The mRNA level of the DMSO + BCG sample was set as $100 \%$, and the rest were compared to the DMSO + BCG sample to obtain a percentage value. (B) Culture supernatants were collected after 24 hours. The levels of IL-6, IL-8, IL-10 and TNF- $\alpha$ in the supernatants were measured by ELISA. The individual cytokine level in the supernatant of the DMSO + BCG sample was set as $100 \%$, and the rest were compared to it to obtain a percentage value. Results are shown as mean \pm SD from independent experiments on PBMac obtained from three (A) or six (B) different healthy donors. ${ }^{*} P<0.05$, ${ }^{* *} P<$ 0.001 compared to the DMSO + BCG sample (one-way ANOVA, Tukey's test). 


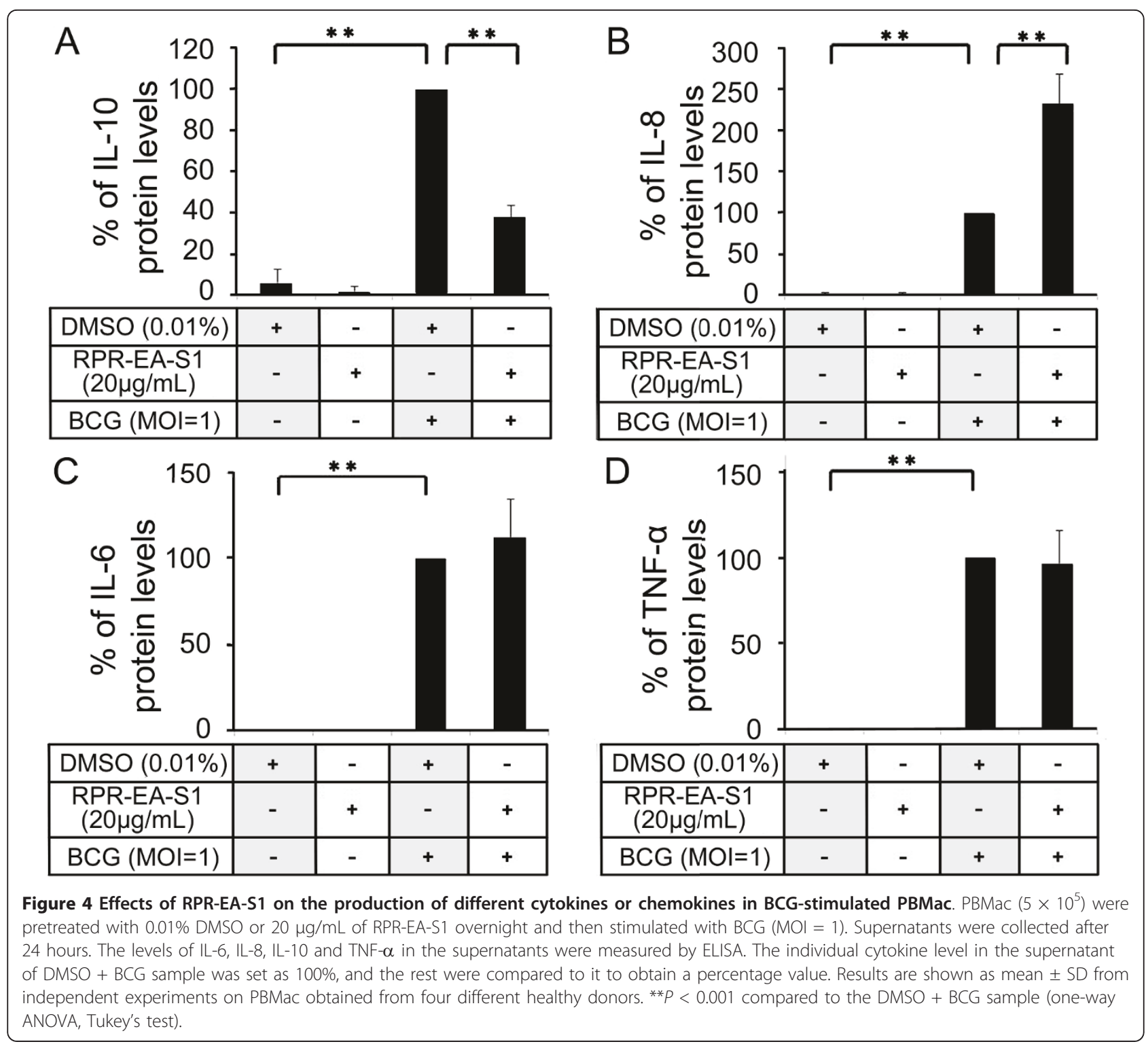

Moreover, the inhibitory effect of RPR-EA-S1 on BCG-induced IL-10 production was in a dose-dependent manner between $5 \mu \mathrm{g} / \mathrm{mL}$ and $50 \mu \mathrm{g} / \mathrm{mL}$ both at the protein and mRNA levels (Figure 5A and $5 \mathrm{~B}$ ). The regulatory effects were significant even at a low concentration of $5 \mu \mathrm{g} / \mathrm{mL}$.

The IL-10 mRNA expression levels were studied over a time course of 24 hours. Figure $5 \mathrm{C}$ shows that the BCG-induced IL-10 expression reached the peak level at three hours before declining to the basal level at 24 hours; however, pretreatment of the cells with RPREA-S1 inhibited BCG-induced IL-10 mRNA expression throughout the time course.

RPR-EA-S1, a fraction of RPR, demonstrated differential effects on cytokine and chemokine expression in
BCG-stimulated PBMac, enhanced BCG-induced IL-8 production and inhibited IL-10 production in a dose and time-dependent manner.

\section{Mechanisms underlying RPR-EA-S1 inhibition of IL-10} expression in BCG-stimulated blood macrophages

After confirming the inhibitory effect of RPR-EA-S1 on BCG-induced IL-10 expression, we investigated the mechanisms underlying the decrease of IL-10 expression. Mitogen-activated protein kinases (MAPK) are involved in IL-10 regulation $[3,25]$. BCG increases the phosphorylation of ERK1/2 and p38 [3]. This study showed that pretreatment with RPR-EA-S1 did not affect the phosphorylation levels of ERK1/2 and p38 induced by BCG stimulation (Figure 6A and 6B). Since 


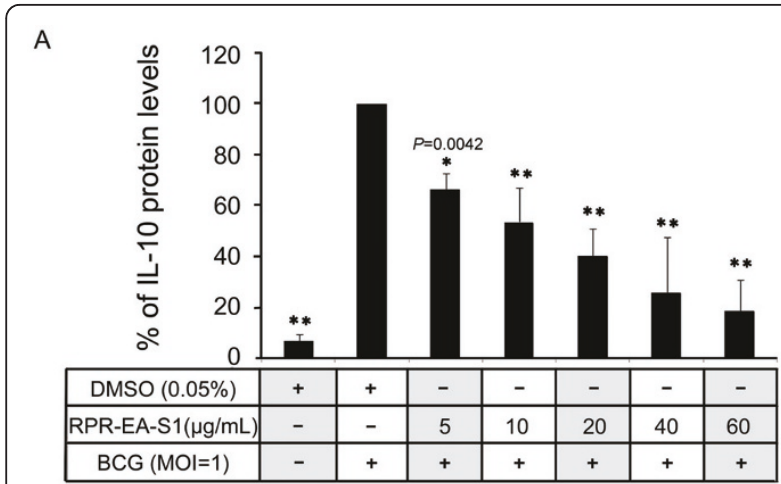

B

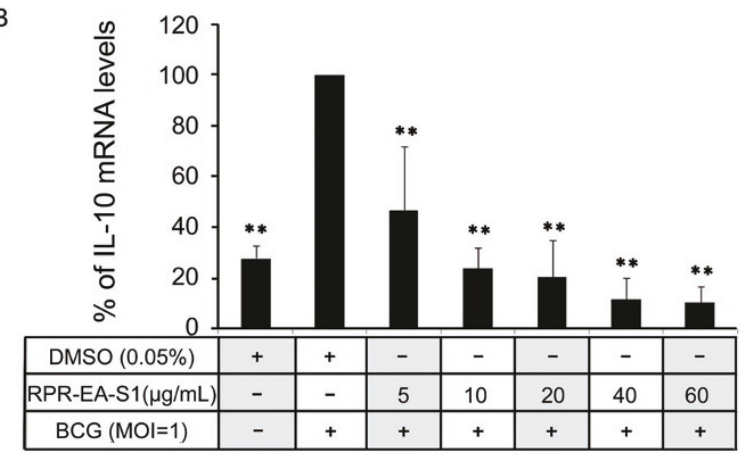

C

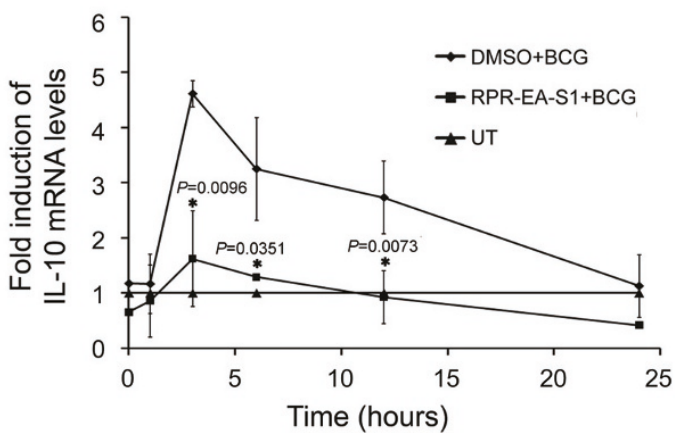

Figure 5 Dose-dependent and time course effects of RPR-EAS1 on the production of IL-10 in BCG-stimulated PBMac. PBMac $\left(5 \times 10^{5}\right)$ were pretreated with $0.05 \%$ DMSO or different dose of RPR-EA-S1 overnight and then stimulated with BCG (MOI =1). (A) Supernatants were collected after 24 hours. The levels of IL-10 in the supernatants were measured by ELISA. (B) Total mRNA was extracted after 3 hours for cDNA synthesis. The levels of mRNA were determined by q-PCR. The mRNA or protein expression levels of DMSO + BCG sample were set as 100\%, and the rest were compared to DMSO + BCG to obtain a percentage value. (C) PBMac $\left(5 \times 10^{5}\right)$ were pretreated with $0.01 \%$ DMSO or $20 \mu \mathrm{g} / \mathrm{mL}$ of RPR-EA-S1 overnight and then stimulated with BCG $(\mathrm{MOI}=1)$ for $0,1,3,6,12$ and 24 hours. Total mRNA was used to synthesize cDNA. The levels of IL-10 mRNA were determined by q$P C R$. Results are shown as mean \pm SD from independent experiments on PBMac obtained from three different healthy donors. ${ }^{*} P<0.05$, ${ }^{* *} P<0.0001$ compared to the DMSO + BCG sample (one-way ANOVA, Tukey's test for Figures $5 \mathrm{~A}$ and $\mathrm{B}$, t-test for Figure 5C).
Akt/GSK3 $\beta$ is a key pathway involved in BCG-induced IL-10 expression [30], we examined the effect of RPREA-S1 on this pathway. The study found that the phosphorylation of Akt or GSK3 $\beta$, inducible by BCG, was not affected by pretreatment of the cells with RPR-EAS1 (Figure 6A and 6B). Neither MAPK kinases nor the Akt/GSK3 $\beta$ pathway was involved in the inhibitory effects of RPR on BCG-induced IL-10 production.

Downstream of these kinases, specific transcriptional factors may also affect IL-10 expression. Our previous study demonstrated a correlation between the translocation of NF- $\kappa \mathrm{B} 1 \mathrm{p} 50$ into the nucleus and the induction of IL-10 by BCG [30]. In the present study, Western blotting was performed to examine the translocation of $\mathrm{NF}-\kappa \mathrm{B} 1 \mathrm{p} 50$ to the nucleus. The results confirmed the induced translocation of NF- $\kappa \mathrm{B} 1 \mathrm{p} 50$ by BCG while RPR-EA-S1 pretreatment of the cells reduced such effects (Figure 6C and 6D). Similarly, the $\mathrm{I} \kappa \mathrm{B} \alpha$ was degraded after BCG stimulation while pretreatment of the cells with RPR-EA-S1 significantly inhibited this degradation (Figure 6C and 6D).

Suppression of BCG-induced IL-10 by RPR-EA-S1 were achieved through suppression of $\mathrm{I} \kappa \mathrm{B} \alpha$ degradation and inhibition of NF- $\kappa \mathrm{B} 1$ p50 translocation to the nucleus (Figure 7).

GC-MS analysis of the chemical constituents of RPR-EA-S1 To further investigate the chemical components of RPREA-S1, we performed GC-MS analysis (Additional files 5 and 6). The mass spectra generated from the extracts were compared to the compounds in NIST GC-MS library. Two major groups of compounds were found in RPR-EA-S1, namely phenols (including hydroquinone, 4-hydroxybenzoic acid and ferulic acid) and fatty acids (including unsaturated and saturated fatty acids).

\section{Discussion}

Recent resurgence of mycobacterial infection is in part due to the spread of AIDS in developing countries. Combined administration of specific anti-mycobacterial drugs is the current TB treatment recommended by the World Health Organization [49]. With increases in multidrugresistant-TB (MDR-TB) and extensively drug-resistant (XDR)-TB strains, the need to develop new anti-Mtb drugs is urgent and immuno-modulatory agents have been considered to enhance TB treatment [50].

We demonstrated that the crude RPR extract and its fraction RPR-EA-S1 augmented BCG-induced IL-8 expression (Figure 3 and 4). Decreased IL-8 secretion was observed in HIV-infected patients with miliary TB [20]. In vivo studies showed that anti-IL-8 antibody inhibited the formation of granuloma in rabbits [51], 


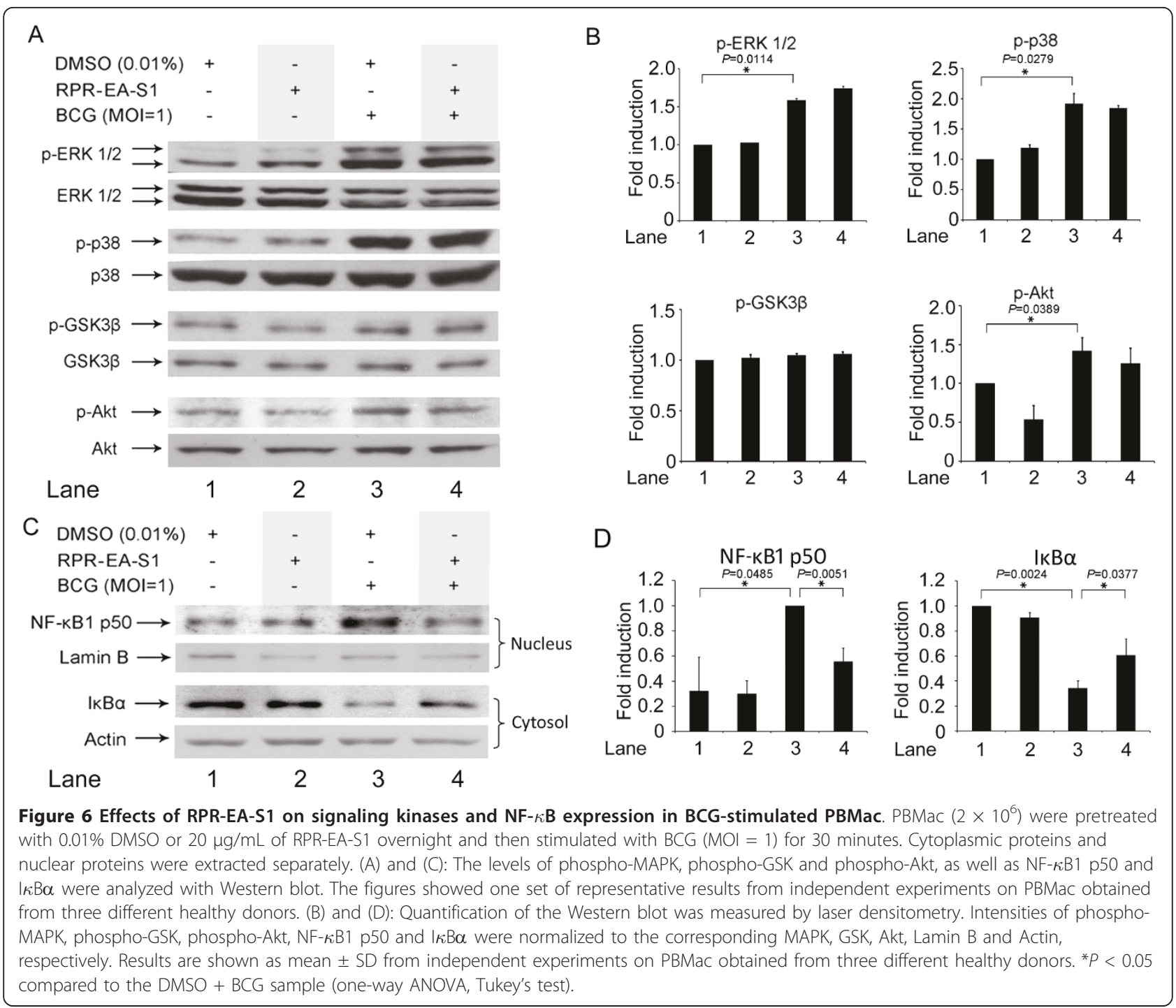

suggesting a significant role for IL- 8 in controlling Mtb infection by the host immunity. Recent studies showed that IL-8 attracted neutrophils and T lymphocytes to the infection sites for the formation of granuloma and augmentation of cell mediated immunity [52]. IL-8 also activated neutrophils to exhibit bactericidal responses [53]. Therefore, the enhanced IL- 8 induction by RPR may be beneficial to the initiation of host immune responses against $\mathrm{Mtb}$ and the subsequent formation of the granuloma in human [51].

We also showed that crude RPR extract and its fraction RPR-EA-S1 can inhibit BCG-induced IL-10 expression (Figure 3, 4, 5). IL-10 is a well known antiinflammatory cytokine produced by macrophages and $\mathrm{T}$ cells during Mtb infection [3]. The relationship between IL-10 production and TB progression was well observed in both animal and human studies [32,33,36]. Recent studies revealed that Mtb utilized IL-10 to evade the host immunity. Firstly, induction of IL-10 inhibited the production of bactericidal molecules including NO and RNIs by macrophages [54]. Secondly, IL-10 suppressed pro-inflammatory cytokines such as IL-12, TNF- $\alpha$ and IFN- $\gamma$, resulting in reduced Th1 cell immunity, CD4+ and CD8+ lytic activity, as well as delayed macrophage activation [31]. Thirdly, IL-10 suppressed antigen presentation by down-regulating $\mathrm{MHC}$ and other co-stimulatory molecules on the cell surface of monocytes/ macrophages [31]. We recently showed that this effect was due to IL-10 activation of STAT3 to suppress cathepsin $S$ expression [29]. Fourthly, IL-10 inhibited TNF- $\alpha$ activity by down-regulating TNF- $\alpha$ expression and inducing soluble TNF receptor 2, leading to reduced apoptosis and increased pathogen survival [55]. Fifthly, macrophage-derived IL-10 triggered alternative macrophage activation in Mtb infection, in which arginase- 1 gene expression was strikingly enhanced. In turn, 


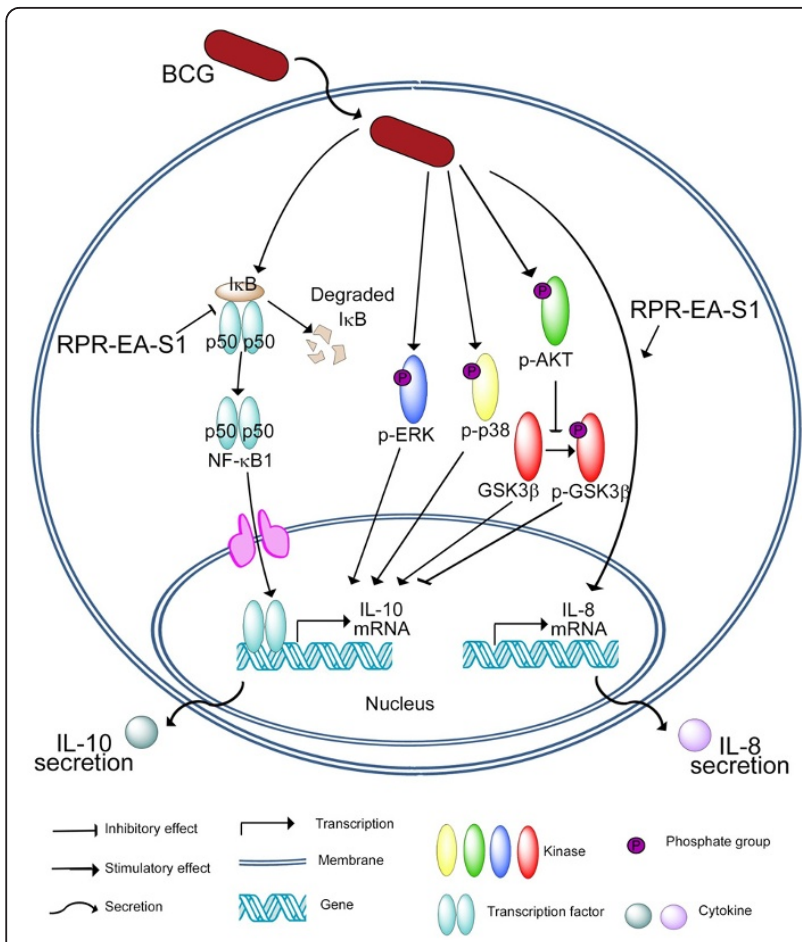

Figure 7 Mechanisms underlying the immunomodulation effects of RPR-EA-S1. In BCG-stimulated macrophages, RPR-EA-S1 can specifically inhibit IL-10 production and yet enhance IL-8 expression. RPR-EA-S1 did not affect the phosphorylation of cellular protein kinases including ERK, p38, Akt and GSK3ß. Its inhibitory effects in BCG-activated IL-10 expression may be, at least in part, through the suppression of the degradation of $\mid \kappa B \alpha$ in the cytoplasm and thus inhibited the translocation of transcription factor NF- $\kappa \mathrm{B} 1 \mathrm{p} 50$ to the nucleus.

arginase-1 negatively regulated microbicidal mechanisms in macrophages and promotes Mtb recrudescence [56]. The inhibitory effects of RPR on BCG-induced IL-10 production may have a beneficial effect on the host for the reversal of the immunosuppressive effects of IL-10 thereby speeding up the killing of Mtb.

Multiple pathways are involved in the regulation of BCG-induced IL-10 expression, including ERK1/2, p38 and PI3K/GSK3 $[3,30]$. In the present study, RPR showed no effect on either of these pathways (Figure 6A and $6 \mathrm{~B}$ ); however, RPR inhibited NF- $\kappa \mathrm{B} 1$ p50 translocation to the nucleus (Figure $6 \mathrm{C}$ and $6 \mathrm{D}$ ). NF- $\kappa \mathrm{B}$ plays a role in promoting the production of cytokines [57]. $\mathrm{NF}-\kappa \mathrm{B}$ is a family of transcriptional factors, including RelA (p65), NF- $\kappa$ B1 (p50 and p105), NF- $\kappa$ B2 (p52 and p100), c-Rel and RelB, bound with an inhibitory protein named $\mathrm{I} \kappa \mathrm{B}$ in the cytoplasm. After stimulation, $\mathrm{I} \kappa \mathrm{B}$ undergoes phosphorylation and degradation, resulting in the release of NF- $\kappa \mathrm{B}$ for translocation to the nucleus, leading to transcription of their regulated target genes [58]. Among members of the NF- $\kappa \mathrm{B}$ family, NF- $\kappa \mathrm{B} 1$ p50/p50 homodimer was involved in IL-10 transcription [59]. In murine macrophages, NF- $\kappa$ B1 p50/p50 homodimer activated transcription of IL-10 together with the CREB protein [59]. Macrophages from NF- $\kappa$ B1 p50 knock-out mice expressed less IL-10 compared to normal mice upon lipopolysaccharide challenge [59]. The present study shows that RPR-EA-S1 significantly reduced the degradation of $\mathrm{I} \kappa \mathrm{B} \alpha$ in the cytoplasm and inhibited the translocation of NF- $\kappa \mathrm{B} 1 \mathrm{p} 50$ to the nucleus in BCG-induced human blood macrophages (Figure 6). Therefore, the inhibition of IL-10 by RPREA-S1 may be mediated by the effects of its constituents on NF- $\kappa \mathrm{B} 1$ translocation (Figure 7 ).

While NF- $\kappa$ B pathway also regulates IL-6, IL- 8 and TNF- $\alpha$, previous studies indicated that the transcriptions of IL- 6, IL- 8 and TNF- $\alpha$ were not mainly regulated by $\mathrm{NF}-\kappa \mathrm{B} 1$ p50 homodimer [59-61]. Instead, silencing of NF- $\kappa \mathrm{B}$ p 65 rather than p50 gene was effective in down-regulating TNF- $\alpha$ induced IL- 6 and IL-8 mRNA synthesis [61]. In luciferase activity assays of the TNF- $\alpha$ promoter, p50 plays little role in driving the transcription, while c-Rel and p65 plays dominant roles in inducing the transcription [60]. Therefore, the inhibition of NF- $\kappa$ B1 p50 translocation to the nucleus cannot affect BCG-induced IL-6, IL- 8 and TNF- $\alpha$ expression. Moreover, the transcriptional regulation of cytokines involved multiple transcriptional factors and was inducer-dependent [62-64]. For example, respiratory syncytial virus (RSV) may increase IL-8 production in the airway epithelium partly via the activation of transcription factors including NF- $\kappa \mathrm{B}$ and NF-IL-6 [65] whereas $\mathrm{AP}-1$ and NF- $\kappa \mathrm{B}$ are essential transcription factors for IL-1 $\beta$-induced IL-8 gene expression [66]. In BCG stimulated macrophages, it is possible that in addition to NF- $\kappa \mathrm{B}$, multiple transcriptional factors may contribute to the expression of IL- 6 , IL- 8 and TNF- $\alpha$. The inhibition of NF- $\kappa \mathrm{B}$ pathway may be compensated by other transcriptional factors. This may also explain why the BCG-induced IL-6, IL- 8 and TNF- $\alpha$ expression were not inhibited by RPR-EA-S1.

The major groups of compounds in the RPR-EA-S1 fraction were phenols and fatty acids. Both phenols and fatty acids are biologically active compounds commonly present in the genus of Paeonia [67-69]. For example, ferulic acid, one of the phenols isolated from Paeonia, scavenges free reactive radicals as determined by DPPH (1, 1-Diphenyl-2-picrylhydrazyl) assay and inhibits lipid peroxidation and protects DNA from oxidative damage [69]. Phenylacetic acid, plant hormone that had been used to treat type II hyperammonemia [70], was also detected in RPR-EA-S1. Our future studies will isolate the compounds responsible for the immuno-regulatory effects of RPR-EA-S1. 


\section{Conclusion}

RPR crude extracts and its fraction RPR-EA-S1 specifically inhibited anti-inflammatory cytokine IL-10 and enhanced pro-inflammatory chemokine IL-8 expression in BCGactivated PBMac. The inhibitory effects of RPR-EA-S1 on IL-10 expression in BCG-activated PBMac may be due to the reduced nuclear translocation of NF- $\kappa \mathrm{B} 1 \mathrm{p} 50$.

\section{Additional material}

\begin{tabular}{|c|c|c|}
\hline \multicolumn{3}{|c|}{$\begin{array}{l}\text { Additional file 1: Effects of different RPR fractions on th } \\
\text { viability of human PBMac. PBMac }\left(5 \times 10^{5}\right) \text { were treated } \\
\text { doses of RPR fractions for } 48 \text { hours. The cell viability was te } \\
\text { assay. Results are shown as mean } \pm \text { SD from independent } \\
\text { on PBMac obtained from three different healthy donors. }{ }^{*} P \\
\text { compared to the DMSO treated sample (one-way ANOVA, T }\end{array}$} \\
\hline \multicolumn{3}{|c|}{$\begin{array}{l}\text { Additional file 2: Effects of different RPR-EA subfraction } \\
\text { viability of human PBMac. PBMac }\left(5 \times 10^{5}\right) \text { were treated } \\
\text { doses of extracts for } 48 \text { hours. The cell viability was tested } \\
\text { Results are shown as mean } \pm \text { SD from independent experir } \\
\text { PBMac obtained from three different healthy donors. }\end{array}$} \\
\hline \multirow{3}{*}{\multicolumn{3}{|c|}{$\begin{array}{l}\text { Additional file 3: HPLC chromatogram of RPR, RPR-EA } \\
\text { S1. The HPLC was performed by using a reverse-phase HPL } \\
\text { (Lichrospher } 100 \mathrm{RP} \text { C18 EC } 5 \mu \mathrm{m}, 250 \times 4.6 \mathrm{~mm} \text { ID) and } \\
\text { wavelength }(\mathrm{WL}) \text { was set at } 210 \mathrm{~nm} \text {. The flow rate was } 1 \mathrm{~m} \\
\text { solvents used in gradient elution were (A) water and (B) ac } \\
\left(\mathrm{CH}_{3} \mathrm{CN}\right) \text {. The program was set as follows. } \\
\text { Time (Minutes) \% Solvent (A) \% Solvent (B) }\end{array}$}} \\
\hline & & \\
\hline & & \\
\hline $0 \quad 90$ & & \\
\hline 60 & & \\
\hline 10 & & \\
\hline 10 & & \\
\hline 90 & & \\
\hline & & \\
\hline
\end{tabular}

Additional file 4: Effects of three different batches of RPR extracts on cytokine expression in BCG-stimulated PBMac. PBMac $\left(5 \times 10^{5}\right)$ were pretreated with $0.1 \%$ DMSO or $100 \mu \mathrm{g} / \mathrm{mL}$ of different batches of RPR extracts (R1, R2 and R3) overnight and then stimulated with BCG $(\mathrm{MOI}=1)$. Supernatants were collected after 24 hours. The levels of IL-6, $\mathrm{IL}-8, \mathrm{IL}-10$ and TNF- $\alpha$ in the supernatants were measured by ELISA. The individual cytokine level in the supernatant of the DMSO + BCG sample was set as $100 \%$, and the rest were compared to it to obtain a percentage value. Results are shown as mean \pm SD from independent experiments on PBMac obtained from three different healthy donors. ${ }^{*} p<0.05,{ }^{* *} p<0.001$ compared to the DMSO + BCG sample (one-way ANOVA, Tukey's test)

Additional file 5: total ion chromatogram of RPR-EA-S1. After reaction with derivatizing agent BSTFA [N, O-bis (trimethylsilyl) trifloroacetamide], RPR-EA-S1 was analyzed by GC-MS equipped with a HP-5MS column $(30 \mathrm{~m} \times 250 \mathrm{~mm} \times 0.25 \mathrm{~mm})$. The spectra of the peaks were compared to the spectra listed in the NIST GC-MS library. Only peaks with $>90 \%$ similarity to the compounds in database were listed in Additional file 6

Additional file 6: Compounds detected in RPR-EA-S1 using GC-MS

\section{Abbreviations}

amu: atom mass units; BCG: Bacillus Calmette-Guerin; BSTFA: bis-trimethyl silyl trifluoroacetamide; $\mathrm{CH}_{3} \mathrm{CN}$ : acetonitrile; $\mathrm{Ct}$ : threshold cycle number; DCs: dendritic cells; EDTA: ethylenediaminetetraacetic acid; El: electron impact ionization; ELISA: enzyme-linked immunosorbent assay; EtOAc: ethyl acetate; EtOH: ethanol; GC-MS: gas chromatography mass spectrometry; GSK3 $\beta$ : glycogen synthase kinase-3 $\beta$; HIV: human immunodeficiency virus; HO-1: heme oxygenase-1; HPLC: high performance liquid chromatography; HSD: Honestly Significant Difference; IFN- $\gamma$ : interferon- $\gamma$; IL-6: interleukin-6; IL-8: interleukin-8; IL-10: interleukin-10; iNOS: inducible nitric oxide synthases; IPP: isopropanol; MAPK: mitogen-activated protein kinases; MDR-TB: multidrugresistant TB; $\mathrm{MeOH}$ : methanol; $\mathrm{MOI}$ : multiplicity of infection; Mtb: Mycobacterium tuberculosis; MTT: 3-(4,5-dimethylthiazol-2-yl)-2,5diphenyltetrazolium bromide; $n$-BuOH: $n$-butanol; $n-\mathrm{C}_{6} \mathrm{H}_{14}$ : hexane; NF-kB1 p50: nuclear factor-KB1 p50; NO: nitric oxide; PBMac: peripheral blood monocytes-derived macrophages; PBS: phosphate buffered saline; q-PCR: quantitative real-time PCR; RNIs: reactive nitrogen intermediates; ROls: reactive oxygen intermediates; RPR: Radix Paeoniae Rubra; RSV: respiratory syncytial virus; SD: standard deviation; TB: tuberculosis; TBST: tris-buffered saline; Tween-20; TNF-a: tumor necrosis factor alpha; XDR-TB: extensively drug-resistant TB.

\section{Acknowledgements}

LW is a recipient of the HKU postgraduate research studentship. This study was funded by grants to ASL from Prof. Francis SK Lau and Mr William Au Research Fund. The authors wish to thank PuraPharm International for the provision and authentication of medicinal herbs as well as collaborations in the extraction and purification processes.

\section{Author details}

${ }^{1}$ Molecular Chinese Medicine Laboratory, Li Ka Shing Faculty of Medicine, The University of Hong Kong, Pokfulam, Hong Kong SAR, PR China. ${ }^{2}$ Cytokine Biology Group, Department of Paediatrics and Adolescent Medicine, The University of Hong Kong, Pokfulam, Hong Kong SAR, PR China. ${ }^{3}$ Department of Pharmacology and Pharmacy, The University of Hong Kong, Pokfulam, Hong Kong SAR, PR China. ${ }^{4}$ Purapharm International Hong Kong, Central, Hong Kong SAR, PR China.

\section{Authors' contributions}

LW designed and performed the experiments, analyzed the data and wrote the manuscript. CLY, JCL and TCO helped design the study, interpreted the data and revised the manuscript. GC and JZ performed the initial extraction and partial purification of the herb. ASL conceived the idea of this study, designed the experiments, supervised the team and revised the manuscript. All authors read and approved the final version of the manuscript.

\section{Competing interests}

The authors declare that they have no competing interests.

Received: 2 April 2010 Accepted: 30 March 2011

Published: 30 March 2011

\section{References}

1. Global Tuberculosis Control: a Short Update to the 2009 Report. [http:// whqlibdoc.who.int/publications/2009/9789241598866_eng.pdf].

2. Ahmad S, Mokaddas E: Recent advances in the diagnosis and treatment of multidrug-resistant tuberculosis. Respir Med 2009, 103:1777-1790.

3. Cheung BKW, Lee DCW, Li JCB, Lau YL, Lau ASY: A role for doublestranded RNA-activated protein kinase PKR in Mycobacterium-induced cytokine expression. J Immunol 2005, 175:7218-7225.

4. Mellman I, Steinman RM: Dendritic cells: specialized and regulated antigen processing machines. Cell 2001, 106:255-258.

5. Brown AE, Holzer TJ, Andersen BR: Capacity of human-neutrophils to kill Mycobacterium-tuberculosis. J Infect Dis 1987, 156:985-989.

6. Yoneda T, Ellner JJ: CD4(+) T cell and natural killer cell-dependent killing of Mycobacterium tuberculosis by human monocytes. Am J Respir Crit Care Med 1998, 158:395-403.

7. Boom WH, Canaday DH, Fulton SA, Gehring AJ, Rojas RE, Torres M: Human immunity to M-tuberculosis: T cell subsets and antigen processing. Tuberculosis 2003, 83:98-106.

8. Desjardins M, Huber LA, Parton RG, Griffiths G: Biogenesis of phagolysosomes proceeds through a sequential series of interactions with the endocytic apparatus. J Cell Biol 1994, 124:677-688.

9. Fang FC: Antimicrobial reactive oxygen and nitrogen species: concepts and controversies. Nat Rev Microbiol 2004, 2:820-832.

10. Gutierrez MG, Master SS, Singh SB, Taylor GA, Colombo MI, Deretic V: Autophagy is a defense mechanism inhibiting BCG and Mycobacterium tuberculosis survival in infected macrophages. Cell 2004, 119:753-766.

11. Liu PT, Stenger S, Li HY, Wenzel L, Tan BH, Krutzik SR, Ochoa MT, Schauber J, Wu K, Meinken C, Kamen DL, Wagner M, Bals R, Steinmeyer A, 
Zugel U, Gallo RL, Eisenberg D, Hewison M, Hollis BW, Adams JS, Bloom BR, Modlin RL: Toll-like receptor triggering of a vitamin D-mediated human antimicrobial response. Science 2006, 311:1770-1773.

12. Molloy A, Laochumroonvorapong P, Kaplan G: Apoptosis, but not necrosis, of infected monocytes is coupled with killing of intracellular bacilluscalmette-guerin. J Exp Med 1994, 180:1499-1509.

13. Wang J, Wakeham J, Harkness R, Xing Z: Macrophages are a significant source of type 1 cytokines during mycobacterial infection. J Clin Invest 1999, 103:1023-1029

14. Flesch IEA, Kaufmann SHE: Activation of tuberculostatic macrophage functions by gamma-interferon, interleukin-4, and tumor-necrosis-factor. Infect Immun 1990, 58:2675-2677.

15. Flynn JL, Goldstein MM, Chan J, Triebold KJ, Pfeffer K, Lowenstein CJ, Schreiber R, Mak TW, Bloom BR: Tumor-necrosis-factor-alpha is required in the protective immune-response against Mycobacterium-tuberculosis in mice. Immunity 1995, 2:561-572.

16. Saunders BM, Frank AA, Orme IM, Cooper AM: Interleukin-6 induces early gamma interferon production in the infected lung but is not required for generation of specific immunity to Mycobacterium tuberculosis infection. Infect Immun 2000, 68:3322-3326.

17. Munk ME, Emoto M: Functions of T-cell subsets and cytokines in Mycobacterial infections. Eur Respir J 1995, 8:S668-S675.

18. Hoffmann E, Dittrich-Breiholz O, Holtmann H, Kracht M: Multiple control of interleukin-8 gene expression. J Leukoc Biol 2002, 72:847-855.

19. Dlugovitzky D, Rateni L, TorresMorales A, RuizSilva J, Pinesky R, Canosa B, Molteni O, Bottasso O: Levels of interleukin-8 in tuberculous pleurisy and the profile of immunocompetent cells in pleural and peripheral compartments. Immunol Lett 1997, 55:35-39.

20. Law KF, Jagirdar J, Weiden MD, Bodkin M, Rom WN: Tuberculosis in HIVpositive patients: Cellular response and immune activation in the lung. Am J Respir Crit Care Med 1996, 153:1377-1384.

21. Pace E, Gjomarkaj M, Melis M, Profita M, Spatafora M, Vignola AM, Bonsignore G, Mody CH: Interleukin-8 induces lymphocyte chemotaxis into the pleural space - role of pleural macrophages. Am J Respir Crit Care Med 1999, 159:1592-1599.

22. Mosser DM, Zhang X: Interleukin-10: new perspectives on an old cytokine. Immunol Rev 2008, 226:205-218.

23. O'Garra A, Vieira P: Regulatory T cells and mechanisms of immune system control. Nat Med 2004, 10:801-805.

24. Fillatreau S, Gray D, Anderton SM: Not always the bad guys: $B$ cells as regulators of autoimmune pathology. Nat Rev Immunol 2008, 8:391-397.

25. Li JCB, Lau ASY: A role for mitogen-activated protein kinase and Ets-1 in the induction of interleukin-10 transcription by human immunodeficiency virus-1 Tat. Immunology 2007, 121:337-348.

26. Li JCB, Lee DCW, Cheung BKW, Lau ASY: Mechanisms for HIV Tat upregulation of IL-10 and other cytokine expression: kinase signaling and PKR-mediated immune response. FEBS Lett 2005, 579:3055-3062.

27. Bogdan C, Vodovotz Y, Nathan C: Macrophage Deactivation by Interleukin-10. J Exp Med 1991, 174:1549-1555.

28. Flesch IEA, Kaufmann SHE: Role of cytokines in tuberculosis. Immunobiology 1993, 189:316-339.

29. Chan LLY, Cheung BKW, Li JCB, Lau ASY: A role for STAT3 and cathepsin S in IL-10 downregulation of IFN- $\gamma$-induced MHC class II molecule on primary human blood macrophages. J Leukoc Biol 2010, 88:303-311.

30. Chan MMP, Cheung BKW, Li JCB, Chan LLY, Lau ASY: A role for glycogen synthase kinase- 3 in antagonizing mycobacterial immune evasion by negatively regulating IL-10 induction. I Leukoc Biol 2009, 86:283-291.

31. Moore KW, Malefyt RD, Coffman RL, O'Garra A: Interleukin-10 and the interleukin-10 receptor. Annu Rev Immunol 2001, 19:683-765.

32. Turner J, Gonzalez-Juarrero M, Ellis DL, Basaraba RJ, Kipnis A, Orme IM Cooper AM: In vivo IL-10 production reactivates chronic pulmonary tuberculosis in C57BL/6 mice. J Immunol 2002, 169:6343-6351.

33. Jacobs M, Brown N, Allie N, Gulert R, Ryffel B: Increased resistance to mycobacterial infection in the absence of interleukin-10. Immunology 2000, 100:494-501.

34. Lee JS, Song CH, Kim CH, Kong SJ, Shon MH, Kim HJ, Park JK, Paik TH, Jo EK: Profiles of IFN-gamma and its regulatory cytokines (IL-12, IL18 and IL-10) in peripheral blood mononuclear cells from patients with multidrug-resistant tuberculosis. Clin Exp Immunol 2002, 128:516-524.
35. Torres M, Herrera T, Villareal H, Rich EA, Sada E: Cytokine profiles for peripheral blood lymphocytes from patients with active pulmonary tuberculosis and healthy household contacts in response to the 30kilodalton antigen of Mycobacterium tuberculosis. Infect Immun 1998, 66:176-180.

36. Boussiotis VA, Tsai EY, Yunis EJ, Thim S, Delgado JC, Dascher CC, Berezovskaya A, Rousset D, Reynes JM, Goldfeld AE: IL-10-producing T cells suppress immune responses in anergic tuberculosis patients. J Clin Invest 2000, 105:1317-1324.

37. Zhu YP: Chinese Materia Medica: Chemistry, Pharmacology, and Applications Amsterdam: OPA; Harwood Academic; 1998.

38. Wu SH, Wu DG, Chen YW: Chemical constituents and bioactivities of plants from the Genus Paeonia. Chem Biodivers 2010, 7:90-104.

39. Zhao Z: An Illustrated Chinese Materia Medica in Hong Kong Hong Kong: School of Chinese Medicine, Hong Kong Baptist University; 2004.

40. Guo S: Tuberculose pleural effusion treated by xiongmoyan decoction plus Western drugs. Shanxi J Tradit Chin Med 2007, 28:1580-1581.

41. Chen C, Zhang F, Xia ZY, Lin H, Mo AS: Protective effects of pretreatment with Radix Paeoniae Rubra on acute lung injury induced by intestinal ischemia/reperfusion in rats. Chin J Traumatol 2008, 11:37-41.

42. Zhan LY, Xia ZY, Chen C, Wang XY: Effect of Radix Paeoniae Rubra on the expression of $\mathrm{HO}^{-1}$ and $\mathrm{NOS}$ in rats with endotoxin-induced acute lung injury. Chin J Traumatol 2006, 9:181-186.

43. Sun WY, Wei W, Gui SY, Wu L, Wang H: Protective effect of extract from Paeonia lactiflora and Astragalus membranaceus against liver injury induced by Bacillus Calmette-Guerin and lipopolysaccharide in mice. Basic Clin Pharmacol Toxicol 2008, 103:143-149.

44. The State Pharmacopoeia Commission of the People's Repubilic of China: Pharmacopoeia of the People's Republic of China (Chinese edition) Beijing: Chemical Industry Press; 2005.

45. Livak KJ, Schmittgen TD: Analysis of relative gene expression data using real-time quantitative PCR and the 2(T)(-Delta Delta C) method. Methods 2001, 25:402-408.

46. Schreiber E, Matthias P, Muller MM, Schaffner W: Rapid detection of octamer binding-proteins with mini-extracts, prepared from a small number of cells. Nucleic Acids Res 1989, 17:6419-6419.

47. Yang CLH, Chik SCC, Li JCB, Cheung BKW, Lau ASY: Identification of the bioactive constituent and its mechanisms of action in mediating the anti-inflammatory effects of black cohosh and related Cimicifuga species on human primary blood macrophages. J Med Chem 2009, 52:6707-6715.

48. Lee DCW, Yang CLH, Chik SCC, Li JCB, Rong JH, Chan GCF, Lau ASY: Bioactivity-guided identification and cell signaling technology to delineate the immunomodulatory effects of Panax ginseng on human promonocytic U937 cells. J Transl Med 2009, 7:34.

49. Ducati RG, Ruffino-Netto A, Basso LA, Santos DS: The resumption of consumption - A review on tuberculosis. Mem Inst Oswaldo Cruz 2006, 101:697-714.

50. Iseman MD: Tuberculosis therapy: past, present and future. Eur Respir J 2002, 20:87s-94s

51. Larsen CG, Thomsen MK, Gesser B, Thomsen PD, Deleuran BW, Nowak J, Skodt V, Thomsen HK, Deleuran M, Thestrup-Pedersen K: The delayed-type hypersensitivity reaction is dependent on II-8 - inhibition of a tuberculin skin reaction by an anti-II-8 monoclonal-antibody. J Immunol 1995, 155:2151-2157.

52. Mukaida N: Pathophysiological roles of interleukin-8/CXCL8 in pulmonary diseases. Am J Physiol Lung Cell Mol Physiol 2003, 284:L566-L577.

53. Godaly G, Young DB: Mycobacterium bovis bacille Calmette Guerin infection of human neutrophils induces CXCL8 secretion by MyD88dependent TLR2 and TLR4 activation. Cell Microbiol 2005, 7:591-601.

54. Cunha FQ, Moncada S, Liew FY: Interleukin-10 (II-10) inhibits the induction of nitric-oxide synthase by interferon-gamma in murine macrophages. Biochem Biophys Res Commun 1992, 182:1155-1159.

55. Balcewicz-Sablinska MK, Keane J, Kornfeld H, Remold HG: Pathogenic Mycobacterium tuberculosis evades apoptosis of host macrophages by release of TNF-R2, resulting in inactivation of TNF-alpha. J Immunol 1998, 161:2636-2641.

56. Schreiber T, Ehlers S, Heitmann L, Rausch A, Mages J, Murray PJ, Lang R, Holscher C: Autocrine IL-10 induces hallmarks of alternative activation in macrophages and suppresses antituberculosis effector mechanisms without compromising T cell immunity. J Immunol 2009, 183:1301-1312. 
57. Ghosh S, Hayden MS: New regulators of NF-kappa B in inflammation. Nat Rev Immunol 2008, 8:837-848.

58. Ghosh S, May MJ, Kopp EB: NF-kappa B and rel proteins: evolutionarily conserved mediators of immune responses. Annu Rev Immunol 1998, 16:225-260.

59. Cao SJ, Zhang X, Edwards JP, Mosser DM: NF-kappa B1 (p50) homodimers differentially regulate pro- and anti-inflammatory cytokines in macrophages. J Biol Chem 2006, 281:26041-26050.

60. Lee UJ, Choung SR, Prakash KVB, Lee EJ, Lee MY, Kim YJ, Han CW, Choi YC: Dual knockdown of p65 and p50 subunits of NF-kappaB by siRNA inhibits the induction of inflammatory cytokines and significantly enhance apoptosis in human primary synoviocytes treated with tumor necrosis factor-alpha. Mol Biol Rep 2008, 35:291-298.

61. Kunsch C, Rosen CA: Nf-Kappa-B subunit-specific regulation of the interleukin-8 promoter. Mol Cell Biol 1993, 13:6137-6146.

62. Gray JS, Pestka JJ: Transcriptional regulation of deoxynivalenol-induced IL-8 expression in human monocytes. Toxicol Sci 2007, 99:502-511.

63. Tang XR, Fenton MJ, Amar S: Identification and functional characterization of a novel binding site on TNF-alpha promoter. Proc Natl Acad Sci USA 2003, 100:4096-4101.

64. Hershko DD, Robb BW, Luo GJ, Hasselgren PO: Multiple transcription factors regulating the IL- 6 gene are activated by CAMP in cultured Caco2 cells. Am J Physiol Regul Integr Comp Physiol 2002, 283:R1140-R1148.

65. Mastronarde JG, He B, Monick MM, Mukaida N, Matsushima K, Hunninghake GW: Induction of interleukin (IL)-8 gene expression by respiratory syncytial virus involves activation of nuclear factor (NF)kappa B and NF-IL-6. J Infect Dis 1996, 174:262-267.

66. Jung YD, Fan F, McConkey DJ, Jean ME, Liu WB, Reinmuth N, Stoeltzing O, Ahmad SA, Parikh AA, Mukaida N, Ellis LM: Role of P38 MAPK, AP-1, and NF-kappa B in interleukin-1 beta-induced IL-8 expression in human vascular smooth muscle cells. Cytokine 2002, 18:206-213.

67. Galli C, Calder PC: Effects of fat and fatty acid intake on inflammatory and immune responses: a critical review. Ann Nutr Metab 2009, 55:123-139.

68. Chae HS, Kang OH, Lee YS, Choi JG, Oh YC, Jang HJ, Kim MS, Kim JH, Jeong SI, Kwon DY: Inhibition of LPS-induced iNOS, COX-2 and inflammatory mediator expression by paeonol through the MAPKs inactivation in RAW 264.7 cells. Am J Chin Med 2009, 37:181-194.

69. Lee SC, Kwon YS, Son KH, Kim HP, Heo MY: Antioxidative constituents from Paeonia lactiflora. Arch Pharm Res 2005, 28:775-783.

70. Scaglia F, Carter S, O'Brien WE, Lee B: Effect of alternative pathway therapy on branched chain amino acid metabolism in urea cycle disorder patients. Mol Genet Metab 2004, 81:S79-S85.

doi:10.1186/1749-8546-6-14

Cite this article as: Wang et al:: Differential effects of Radix Paeoniae Rubra (Chishao) on cytokine and chemokine expression inducible by mycobacteria. Chinese Medicine 2011 6:14.

\section{Submit your next manuscript to BioMed Central and take full advantage of:}

- Convenient online submission

- Thorough peer review

- No space constraints or color figure charges

- Immediate publication on acceptance

- Inclusion in PubMed, CAS, Scopus and Google Scholar

- Research which is freely available for redistribution

Submit your manuscript at www.biomedcentral.com/submit
Biomed Central 